\title{
Editorial
}

International Archives of Otorhinolaryngology

Editorial

$17^{\text {th }}$ Volume (3) - Jul/Aug/September - 2013

\section{International Archives of Otorhinolaryngology and Thieme Medical Publishers}

On 16 April 2013, the Otorhinolaryngology Foundation signed a partnership with Thieme Medical Publishers for the publication of the International Archives of Otorhinolaryngology, beginning with this year's 4 th edition.

Thieme, a German publishing company based in Stuttgart with a 125-year history, is one of the most important publishers of medical books and journals in the world. It publishes 130 diversified medical journals and 70 new books a year.

The International Archives of Otorhinolaryngology is a journal sponsored by the Otorhinolaryngology Foundation and the Societas Oto-Rhino-Laryngologica Latina, a medical society founded in 1924. It has been continuously published for the last 17 years and is the first electronic journal of otorhinolaryngology in the world. This scientific journal is reviewed by an international editorial board and independent peer reviewers and is currently supported by FAPESP (Foundation for Research Support of the State of Sao Paulo).

This partnership is a major breakthrough for Brazilian science, since our journal, as part of Thieme's portfolio, will partake of the publisher's quality standards and achieve more international visibility.

With this partnership, the International Archives of Otorhinolaryngology will be added to the most important indexations of medicine in the medium term, thus supplementing its already established academic presence. It will also increase the contributions from all around the world. This way, we hope the journal will become, soon, the major vehicle for research in the field of otorhinolaryngology, speech therapy, and related sciences in Latin America. The authors who publish in our journal will thus have an international impact comparable to researchers whose work appears in other renowned periodicals.

Congratulations to all who have published in our journal and who have induced Thieme, which took notice of the quality of its contents and its importance among Brazilian experts, to choose it as its starter in Brazil.

Finally, this partnership was made possible by the visionary mission of Professor Ricardo Bento, President of the Board of Trustees of the Otorhinolaryngology Foundation; the perseverance and encouragement of Professor Richard Voegels; the institutional and quality commitment of Professor Geraldo Pereira Jotz, Editor-in-Chief; and of Dr. Aline Bittencourt, Co-Editor; together with the professional dedication of Adilson Montefusco, librarian in charge. This partnership was signed in Sao Paulo in the presence of Mr. Daniel Schiff, Senior Vice President of Thieme Publishers, and Mrs. Michele Aranha, representative in Brazil of Thieme Publishers.

For future issues, we will be changing the system of online manuscript submission and review, which will be managed by ScholarOne (http://mc.manuscriptcentral.com/iaorl)

Best regards,

Geraldo Pereira Jotz

Editor-in-Chief

International Archives of Otorhinolaryngology

Aline Bittencourt

Co-Editor

International Archives of Otorhinolaryngology

Index in LILACS and LILACS-Express - Latindex - DOAJ - FUNPEC-RP SCIELO - SCOPUS 